\title{
Characterization of selective resistance to insulin signaling in the vasculature of obese Zucker ( $\mathrm{fa} / \mathrm{fa}$ ) rats
}

\author{
Zhen Y. Jiang, You-Wei Lin, Allen Clemont, Edward P. Feener, Katherine D. Hein, \\ Masahiko Igarashi, Teruaki Yamauchi, Morris F. White, and George L. King
}

Research Division, Joslin Diabetes Center, Harvard Medical School, Boston, Massachusetts 02215, USA

Address correspondence to: George L. King, Joslin Diabetes Center, One Joslin Place, Boston, Massachusetts 02215, USA. Phone: (617) 732-2662; Fax: (617) 732-2637; E-mail: Kingg@joslin.harvard.edu.

Received for publication December 4, 1998, and accepted in revised form July 7, 1999.

\begin{abstract}
Both insulin resistance and hyperinsulinemia have been reported to be independent risk factors for cardiovascular diseases. However, little is known regarding insulin signaling in the vascular tissues in insulin-resistant states. In this report, insulin signaling on the phosphatidylinositol 3-kinase (PI 3kinase) and mitogen-activated protein (MAP) kinase pathways were compared in vascular tissues of lean and obese Zucker $(f a / f a)$ rats in both ex vivo and in vivo studies. Ex vivo, insulin-stimulated tyrosine phosphorylation of insulin receptor $\beta$ subunits (IR $\beta)$ in the aorta and microvessels of obese rats was significantly decreased compared with lean rats, although the protein levels of IR $\beta$ in the 2 groups were not different. Insulin-induced tyrosine phosphorylation of insulin receptor substrates 1 and 2 (IRS-1 and IRS-2) and their protein levels were decreased in the aorta of obese rats compared with lean rats. The association of $\mathrm{p} 85$ subunit to the IRS proteins and the IRS-associated PI 3-kinase activities stimulated by insulin in the aorta of obese rats were significantly decreased compared with the lean rats. In addition, insulin-stimulated serine phosphorylation of Akt, a downstream kinase of PI 3-kinase pathway, was also reduced significantly in isolated microvessels from obese rats compared with the lean rats. In euglycemic clamp studies, insulin infusion greatly increased tyrosine phosphorylation of IR $\beta$ - and IRS-2-associated PI 3-kinase activity in the aorta of lean rats, but only slight increases were observed in obese rats. In contrast, insulin stimulated tyrosine phosphorylation of MAP kinase (ERK$1 / 2$ ) equally in isolated microvessels of lean and obese rats, although basal tyrosine phosphorylation of ERK-1/2 was higher in the obese rats. To our knowledge, these data provided the first direct measurements of insulin signaling in the vascular tissues, and documented a selective resistance to PI 3kinase (but not to MAP kinase pathway) in the vascular tissues of obese Zucker rats.
\end{abstract}

J. Clin. Invest. 104:447-457 (1999).

\section{Introduction}

Insulin's biological actions in vascular cells include increases in amino acid transport, glycogen synthesis, DNA synthesis, and gene expression $(1,2)$. Insulin also has specific vascular actions, such as enhancing the release of nitric oxide (NO) (3) and regulating mRNA expression of matrix proteins $(4,5)$ and constitutive endothelial NO synthase (eNOS) (6). Physiologically, insulin infusion stimulates local vasodilatation by enhancing NO's action $(7,8)$. Thus, insulin may regulate many vascular functions under physiological conditions.

Insulin resistance and hyperinsulinemia have been associated with the development of cardiovascular diseases and hypertension (9-12). Mechanisms to explain the associations between insulin resistance and cardiovascular diseases have been attributed to insulin's effects on vascular smooth muscle cell (VSMC) growth (2), extracellular matrix production $(4,5)$, renal sodium reabsorption, and adrenergic stimulation $(13,14)$. However, an assumption underlying these theories is that insulin resistance is tissue specific to the muscle and adipose tissues only, whereas vascular and renal tissues remained sensitive to insulin. Otherwise, insulin's growth effects on vascular or renal tissues should also be blunted. However, physiological studies have documented that endothelial functions as measured by insulin-induced vasodilatation are reduced in insulin-resistant and diabetic patients (12), suggesting that vascular cells are also resistant to insulin for some of its physiological actions. To explain these apparent conflicting findings, we have suggested that some of insulin's actions, such as the stimulatory effects on NO production, are selectively inhibited in insulin-resistant states. However, other effects of insulin, such as its growth-promoting actions on VSMCs are unaffected. The result of this selective insulin resistance in the vascular tissues is an enhanced atherosclerotic potential in insulin-resistant states.

A possible explanation for the selective loss of insulin actions in insulin-resistant states may reside in the pleiotropic pathways by which insulin mediates its actions. In nonvascular cells, insulin actions are initiated through binding to the $\alpha$ subunit of insulin receptors (IRs), which activates intrinsic receptor tyrosine kinase (15), resulting in autophosphorylation of insulin receptor $\beta$ subunit (IR $\beta$ ) and tyrosine phosphorylation of intracellular adapter proteins such as IR substrates (IRS-1 and IRS-2) $(16,17)$ and Shc (18). Tyrosine-phosphorylated IRS- 1 or IRS- 2 binds to src-homology 2 (SH2) domains of intracellular proteins, including p85 regulatory subunit of phosphatidylinositol 3-kinase (PI 3-kinase) (19). The 
interaction of IRS and p85 subunit of PI 3-kinase results in the activation of p110 catalytic subunit of PI 3-kinase. Activation of PI 3-kinase pathway by insulin is linked to metabolic functions such as glucose transport $(20,21)$, glycogen, and protein synthesis $(22,23)$. Tyrosine-phosphorylated Shc and IRS proteins can also bind to SH2 domain of GRB2, leading to the activation of the Ras-RafMAP kinase signal pathway $(24,25)$, which is associated with gene expression and cell growth (26-28).

However, in vascular cells, the signal-transduction pathways of insulin have not been measured in vivo directly on vascular tissues. Similar to nonvascular cells, IR are expressed in VSMC or endothelial cells (29). Once bound and phosphorylated, IR will phosphorylate IRS-1, IRS-2, and Shc and activate PI 3-kinase and Raf-MAP kinase pathways $(1,30)$. Biologically, the activation of PI 3-kinase has been linked to NO production, whereas the activation of Raf-MAP kinase pathway is associated with the growth of vascular cells and the expression of extracellular matrix proteins $(3,4,6,31)$.

Thus, it is possible that there is a selective loss of insulin's activation of PI 3-kinase pathway, even though it maintains its effectiveness in activating the MAP-kinase pathway in insulin-resistant states. To test this possibility, we have characterized insulin's actions on PI 3-kinase and MAP kinase, both ex vivo and in vivo, directly on vascular tissues from both lean and obese Zucker $(f a / f a)$ rats. We believe that these results provide the first direct evidence that insulin-stimulated tyrosine phosphorylation of IR and IRS proteins and PI 3-kinase activation were selectively impaired, whereas MAP kinase was not altered in vascular tissues of insulin-resistant animals.

\section{Methods}

Materials. Human recombinant insulin (Human R) was purchased from Lilly Research Laboratories (Indianapolis, Indiana, USA). Polyclonal antibodies against IR $\beta$ (SC-711; epitope corresponding to amino acids $1365-1382$ of human IR $\beta$ ) and IGF- 1 receptor $\beta$ subunit (IGF-1R $\beta$ ) (SC-713; epitope corresponding to amino acids $1347-1366$ of human IGF-1R $\beta$ ) were from Santa Cruz Biotechnology Inc. (Santa Cruz, California, USA). mAb against phosphotyrosine ( $\alpha \mathrm{PY}$ ) and polyclonal antibodies against p85 subunit of PI 3-kinase were purchased from Upstate Biotechnology Inc. (Lake Placid, New York, USA). Polyclonal antibodies against rat IRS-1 (JD229) and IRS-2 (JD110) were raised in rabbits using GST-fusion proteins containing amino acids 735-900 of rat IRS- 1 and amino acids 976-1094 of mouse IRS-2, respectively $(16,17)$. Polyclonal antibodies against $\mathrm{p} 44 / 42$ MAP kinase, tyrosine-phosphorylated MAP kinase, and serine-phosphorylated Akt (PKB) were from New England Biolabs (Beverly, Massachusetts, USA). Rabbit anti-mouse immunoglobulin antibody and anti-human factor VIII antibody were purchased from DAKO Corp. (Carpinteria, California, USA). Donkey anti-rabbit immunoglobulin horseradish peroxidase-linked antibody, enhanced chemiluminescence (ECL) kit, and $\left[{ }^{125} \mathrm{I}\right]$ protein A were from Amersham Life Sciences Inc. (Arlington Heights, Illinois, USA). The $\left[\gamma_{-}{ }^{32} \mathrm{P}\right]$ ATP was from Du Pont NEN Research Products (Wilmington, Delaware, USA).
Phosphatidylinositol was from Avanti Polar Lipids Inc. (Alabaster, Alabama, USA). Silica gel TLC plates were from E. Merck (Darnstadt, Germany). Protein ASepharose 6MB was from Pharmacia Biotech AB (Uppsala, Sweden). PVDF and nitrocellulose paper (0.2 mm) were from Novex (San Diego, California, USA). All other reagents were from Sigma Chemical Co. (St. Louis, Missouri, USA).

Animals. Male obese Zucker rats $(f a / f a)$ and their agematched lean controls $(f a /+)$ were purchased from Harlan Sprague Dawley Inc. (Indianapolis, Indiana, USA). The rats (14 weeks old) were fed standard rodent chow and water ad libitum. Physiological parameters of the Zucker obese and lean rats are described in Table 1 . In ex vivo studies, food was withdrawn 14 hours before experiments were performed. Rats were sacrificed with $\mathrm{CO}_{2}$, and the aorta and epididymal fat-pads were isolated immediately. The aortas were kept in DMEM containing 0.1\% BSA at room temperature for 2 hours before insulin stimulation, and then were frozen with liquid $\mathrm{N}_{2}$ and kept at $-80^{\circ} \mathrm{C}$ for subsequent analysis. Epididymal fat-pads were used for the isolation of microvessels as described below.

Euglycemic byperinsulinemic clamp. In this study, both obese Zucker $f a / f a$ rats and their lean controls (14 weeks old) were randomly divided into control group and insulin infusion group. Eight rats were assigned to each group to study IR tyrosine phosphorylation, and 5 rats were assigned to each group used to study PI 3-kinase activity. Catheters were inserted into the rats' right jugular veins, and another into the left carotid arteries as described previously (32). Rats were allowed to recover from surgery for 5-6 days with standard laboratory chow before the clamp procedure was performed. Rats were fasted overnight (14 hours) before receiving infusion of saline (control group) or insulin at 10 $\mathrm{mU} / \mathrm{kg} / \mathrm{min}$ for 1 hour. The right jugular vein was used for glucose and insulin infusion, and the left carotid artery was used for monitoring blood glucose and plasma insulin levels. Blood glucose samples were taken and monitored every 5 minutes during the infusion. A variable infusion of $20 \%$ glucose solution was started at time 0 and adjusted to clamp the blood glucose level at the basal level before insulin was infused. After 1 hour of study, rats were sacrificed with $\mathrm{CO}_{2}$. The aorta and liver were isolated immediately, frozen with liquid $\mathrm{N}_{2}$, and stored at $-80^{\circ} \mathrm{C}$ for subsequent analysis.

Isolation of microvessels. Microvessels (vascular stroma) were isolated from epididymal fat-pads of Zucker obese and lean rats. Briefly, fat-pads were minced and digested with $0.2 \%$ collagenase (Type I; Worthington Biochemical Corp., Lakewood, New Jersey, USA) in DMEM containing $0.1 \%$ BSA for 30 minutes before homogenizing with a loose Dounce homogenizer, followed by centrifugation at 2060 $g$ for 15 minutes. The pellets of enriched microvessels were washed with DMEM media 3 times and equilibrated at room temperature for 1 hour before insulin treatment. Samples were then immediately frozen with liquid $\mathrm{N}_{2}$ and kept at $-80^{\circ} \mathrm{C}$ for analysis. The purity of the isolated vascular stroma was assessed by staining with hematoxylin and eosin $(\mathrm{H} \& \mathrm{E})$ or by immunohistochemical staining with antibody to factor VIII. Figure 1a shows a typical H\&E stain of blood vessels in the vascular stroma sample. The internal wall of isolated vascular stroma is positively 
stained by anti-factor VIII antibody (Figure 1b), indicating that the stroma is composed of small blood vessels. Vascular stroma from the lean and obese Zucker rats were characterized further by quantifying the contents of vascular smooth muscle-specific $\alpha$ actin ( $\alpha$-SMA), which was detected by immunoblotting with $\mathrm{mAb}$ (Sigma Chemical Co.). As shown in Figure 1c, vascular stroma from lean and obese rats contained the same amount of $\alpha$-SMA, indicating the microvessel contents of the stroma from lean and obese rats were similar.

Immunoprecipitation. Frozen tissues were homogenized in ice-cold lysis buffer containing 50 mM HEPES ( $\mathrm{pH} 7.4$ ), 10 $\mathrm{mM}$ sodium pyrophosphate, $10 \mathrm{mM}$ sodium fluoride, 2 mM EDTA, 2 mM Na $3 V_{4}, 2 \mathrm{mM}$ PMSF, $10 \mu \mathrm{g} / \mathrm{mL}$ aprotinin, $10 \mu \mathrm{g} / \mathrm{mL}$ leupeptin, $1.5 \mathrm{mg} / \mathrm{mL}$ benzamidine, $1 \%$ Triton X-100, and $10 \%$ glycerol. Liver was homogenized on ice with a generator (Polytron PTA 20S; Brinkmann Instruments Inc., Westbury, New York) at medium speed for 30 seconds and left on ice for 30 minutes. Powdered aorta and vascular stroma were homogenized with a glass Dounce homogenizer on ice for at least 80 strokes. Insoluble material was removed by centrifugation at $13,800 \mathrm{~g}$ at $4^{\circ} \mathrm{C}$ for 10 minutes. Supernatant was precipitated with antibodies against $\operatorname{IR} \beta(0.3 \mu \mathrm{g} / \mathrm{mL})$, IRS-1/2 (1:1,000 dilution), or p85 subunit of PI 3-kinase (1:1,000 dilution) for 2 hours, followed by incubation with $60 \mu \mathrm{L}$ of protein A-Sepharose $6 \mathrm{MB}$ for 2 hours at $4^{\circ} \mathrm{C}$. The beads were washed 5 times with lysis buffer before adding Laemmli buffer, and were heated in boiling water for 4 minutes. The protein extracts were used for electrophoresis and immunoblotting studies, as described below.

Western immunoblotting. Immunoprecipitated fractions were separated with SDS-PAGE, electrotransferred to nitrocellulose filter, and immunoblotted as previously described (30). To detect tyrosine phosphorylation of IR, IRS-1, or IRS-2, the blots were first incubated with $\mathrm{mAb}$ $\alpha \mathrm{PY}(1 \mu \mathrm{g} / \mathrm{mL})$ for 1 hour, then with rabbit anti-mouse antibody (1:1,000 dilution) for 2 hours, and finally with $\left.{ }^{[125} \mathrm{I}\right]$ protein $\mathrm{A}$ for 1 hour at room temperature. To detect protein levels of IR $\beta$, IRS-1, IRS-2, and P85 subunit of PI 3kinase, blots were first incubated with polyclonal $\alpha \operatorname{IR} \beta$, $\alpha$ IRS- 1 and $\alpha$ IRS-2, or $\alpha$ p85 antibodies, respectively, and then incubated with $\left[{ }^{125} \mathrm{I}\right]$ protein A for 1 hour at room temperature. All blots were washed with PBS containing $0.02 \%$ Tween-20 for 1 hour at room temperature after each incubation, and $\left.{ }^{[125} \mathrm{I}\right]$ protein A-bound proteins were detected and quantified by PhosphorImager (Molecular Dynamics, Sunnyvale, California, USA).

To quantify the contents of $\alpha$-SMA in microvessels, lysates ( $20 \mu \mathrm{g}$ protein) were separated by SDS-PAGE and electrotransferred to PVDF membranes. The blots were incubated with an $\mathrm{mAb}$ (1:1,000 dilution) against $\alpha$-SMA and a second antibody containing horseradish peroxidase-linked anti-mouse immunoglobulin antibody (1:3,000 dilution; Amersham Life Sciences), and were detected with an ECL kit.

To detect serine phosphorylation of Akt, total lysates $(100 \mu \mathrm{g}$ protein) from microvessels were separated with $8 \%$ SDS-PAGE and electrotransferred to nitrocellulose membranes, which were incubated with anti-phos- pho-(ser-473)-akt antibodies (1:1,000 dilution) overnight at $4^{\circ} \mathrm{C}$, and then with horseradish peroxidase-linked anti-rabbit immunoglobulin antibodies (1:2,000 dilution) for 1 hour at room temperature. The membranes were then washed with buffer after each incubation (PBS [pH 7.4], 0.1\% Tween-20) for 1 hour at room temperature. Finally, the level of serine-phosphorylated Akt was detected with an ECL kit and quantified with a densitometer, with reading performed in the linear range.

The tyrosine phosphorylation and protein levels of p44/42 MAP kinase (ERK-1/2) were determined as follows. Lysates $(50 \mu \mathrm{g}$ protein) from homogenized tissues were separated with $10 \%$ SDS-PAGE and electrotransferred to PVDF membranes, which were incubated with specific antibodies against tyrosine-phosphorylated ERK-1/2 ( $1: 1,000$ dilution) overnight at $4{ }^{\circ} \mathrm{C}$, and then with horseradish peroxidase-linked anti-rabbit immunoglobulin antibodies (1:2,000 dilution) for 1 hour at room temperature. Finally, the level of tyrosine-phosphorylated ERK-1/2 was detected with ECL. To detect the protein levels of ERK$1 / 2$, the membranes were stripped and reblotted with antibodies against ERK-1/2 (1:1,000 dilution), and then with horseradish peroxidase-linked anti-rabbit immunoglobulin antibodies for 1 hour at room temperature. Again, the levels of ERK-1/2 were detected with ECL.

PI 3-kinase assay. PI 3-kinase activity was measured by in vitro phosphorylation of phosphatidylinositol. Briefly, vascular tissues were homogenized, immunoprecipitated with $\alpha$ IRS- 1 or $\alpha$ IRS-2, and PI 3-kinase activities in the immunoprecipitates were measured in the presence of phosphatidylinositol and $\left[\gamma^{32} \mathrm{P}\right] \mathrm{ATP}$ using the method previously described $(30,33)$. The ${ }^{32} \mathrm{P}$-labeled phosphatidylinositol 3-monophosphate was extracted with $\mathrm{CHCl}_{3} / \mathrm{CH}_{3} \mathrm{OH}$, separated by TLC, and quantified by a PhosphorImager.

Statistical analysis. Unless indicated otherwise, comparisons of data presented as mean \pm SD were performed using the Kruskal-Wallis 1-way ANOVA. $P$ values less than 0.05 were considered to be significantly different.

\section{Results}

Ex vivo effect of insulin on tyrosine phosphorylation of IRs in the aorta and microvessels. Insulin's effects on tyrosine phosphorylation of IR $\beta$ in isolated aorta and enriched microvessels (vascular stroma) isolated from Zucker lean $(f a /+)$ and obese $(f a / f a)$ rats were examined ex vivo. All the rats used in all the ex vivo experiments were 14 weeks old,

\section{Table 1}

Characteristics of obese Zucker $(f a / f a)$ rats and their age-matched lean Zucker $(\mathrm{fa} /+)$ controls

\begin{tabular}{lccccc} 
Groups & $\begin{array}{c}\text { Number } \\
\text { of rats }(n)\end{array}$ & $\begin{array}{c}\text { Body weight } \\
(\mathrm{g})\end{array}$ & $\begin{array}{c}\text { Blood glucose } \\
(\mathrm{mg} / \mathrm{dL})\end{array}$ & $\begin{array}{c}\text { Serum insulin } \\
\text { before clamp } \\
(\mu \mathrm{U} / \mathrm{mL})\end{array}$ & $\begin{array}{c}\text { Serum insulin } \\
\text { after clamp } \\
(\mu \mathrm{U} / \mathrm{mL})\end{array}$ \\
Lean control & 13 & $335 \pm 17$ & $89 \pm 8$ & $8 \pm 2$ & $9 \pm 2$ \\
Lean insulin & 13 & $320 \pm 25$ & $86 \pm 10$ & $9 \pm 3$ & $224 \pm 56^{\mathrm{D}}$ \\
fa/fa control & 13 & $490 \pm 32^{\mathrm{A}}$ & $104 \pm 12$ & $262 \pm 52^{\mathrm{C}}$ & $234 \pm 46$ \\
$\mathrm{fa} / \mathrm{fa}$ insulin & 13 & $478 \pm 34^{\mathrm{B}}$ & $101 \pm 10$ & $267 \pm 51^{\mathrm{D}}$ & $480 \pm 78^{\mathrm{E}}$ \\
\hline
\end{tabular}

${ }^{A} P<0.01$ vs. lean control group; unpaired Student's $t$ test. ${ }^{B} P<0.01$ vs. lean insulin group; unpaired Student's $t$ test. ${ }^{C} P<0.001$ vs. lean control group before clamp; paired Student's $t$ test. ${ }^{D} P<0.001$ vs. lean insulin group before clamp; paired Student's $t$ test. ${ }^{E} P<0.005$ vs. fa/fa insulin group before clamp; paired Student's $t$ test. 


\section{Figure 1}

Microvessels isolated from rat epididymal fat-pads. Isolated epididymal fat-pads were digested with collagenase and homogenized as described in Methods. The purity of the isolated microvessels were verified by histochemical staining with H\&E (a) and immunohistochemical staining with factor VIII antibody (b). Immunoblotting with antibody against vascular $\alpha$-SMA was used to compare the quality of isolated microvessels from lean and obese rats $(\mathbf{c})$.

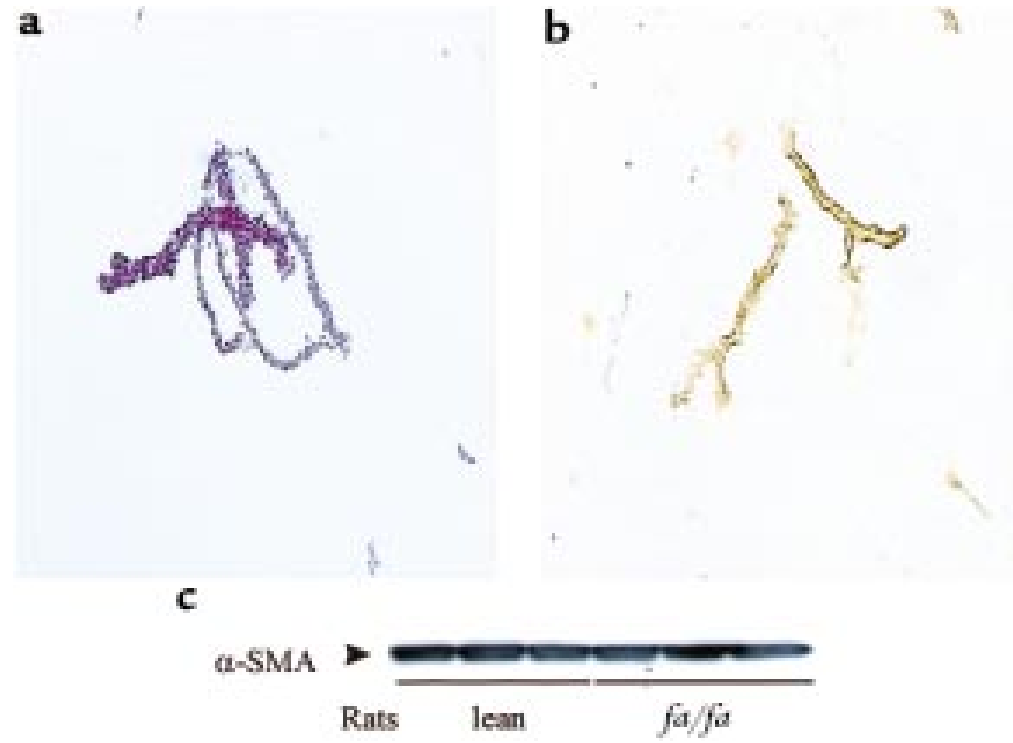

(middle), protein levels of IR were not different between microvessels from Zucker lean and obese rats (Figure 2a).

In isolated aorta immunoblot analysis of tyrosine-phosphorylated proteins in the $\alpha \operatorname{IR} \beta$, immunoprecipitates showed that the basal tyrosine phosphorylation of IR was slightly higher in the aorta from obese rats than from lean rats (Figure $2 b$ ). Insulin-stimulated IR $\beta$ tyrosine phosphorylation was increased by 6.3-fold over the basal level in the aorta from lean rats, whereas only a 2.5 -fold increase was observed in aorta from obese rats, a reduction of $71 \%$ compared with lean rats $(P<0.01)$. No significant differences were found in IR protein levels between the aorta of Zucker lean and obese rats (Figure 2b, middle).

Protein expression and tyrosine phosphorylation of IRS-1/2 and their association with $p 85$ subunit of PI 3-kinase in the aorta. The protein levels of IRS-1 and IRS- 2 in the aorta from control and obese rats were quantitated by immunoprecipitation and immunoblotting with $\alpha$ IRS1 or $\alpha$ IRS- 2 antibodies and showed a decrease of $23 \%$ and $34 \%$, respectively, in the aorta of obese rats compared with lean controls (Figure 3a). In ex vivo experiments, insulin-stimulated (100 nM) increases of 3.6- and 5.3-fold in tyrosine phosphorylation of IRS-1 and IRS-2,

a
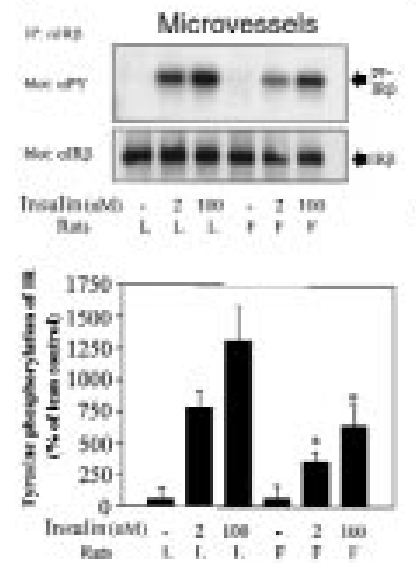

b

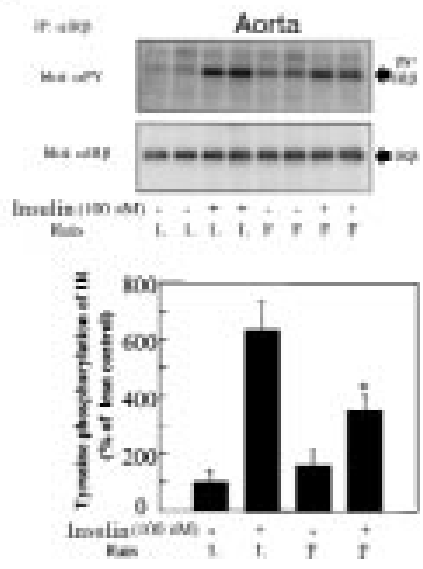

Figure 2

Tyrosine phosphorylation and protein levels of $\operatorname{IR} \beta$ in the aorta and microvessels of obese Zucker fa/fa and lean rats ex vivo. Microvessels (a) and aorta (b) were isolated from lean and obese rats as described in Methods, followed by incubation with or without insulin $(2-100 \mathrm{nM})$ in $\operatorname{DMEM}(0.1 \% \mathrm{BSA})$ for 5 minutes (microvessels) or 30 minutes (aorta) at $37^{\circ} \mathrm{C}$. Equal amounts of protein $(6 \mathrm{mg}$ of microvessel sample and $4 \mathrm{mg}$ of aorta sample) were subjected to immunoprecipitation with $\alpha \operatorname{IR} \beta$ antibody, separated by SDS-PAGE, and immunoblotted with $\alpha$ PY antibody (top panels). Stripped membranes were reblotted with $\alpha$ IR $\beta$ antibody (middle panels). Data (mean $\pm \mathrm{SD} ; n=4$ ) are expressed as relative to control, assigning a value of $100 \%$ to the lean control mean. ${ }^{*} P<0.05$, lean vs. obese tissues incubated with insulin at the same concentrations. 


\section{Figure 3}

Protein levels, tyrosine phosphorylation of IRS-1 and IRS-2, and their association with P85 subunit of PI 3-kinase in the aorta ex vivo. (a) Protein levels of IRS-1 and IRS-2. Isolated aortas were homogenized, and equal amounts of protein (10 $\mathrm{mg}$ ) were subjected to immunoprecipitation with $\alpha$ IRS-1 or $\alpha$ IRS-2 antibodies, separated by SDS-PAGE, and immunoblotted with the same antibody. Data (mean $\pm S D ; n=4$ ) are expressed as relative to control, assigning a value of $100 \%$ to the lean control mean. ${ }^{*} P<0.05$, lean vs. obese. ( $b$ and $\mathbf{c}$ ) Insulin-stimulated tyrosine phosphorylation of IRS-1 and IRS2. Isolated aortas were incubated without or with insulin (100 $\mathrm{nM})$ in DMEM (0.1\% BSA) for 30 minutes at $37^{\circ} \mathrm{C}$. Equal amounts of protein ( $6 \mathrm{mg}$ ) were subjected to immunoprecipitation with $\alpha$ IRS- 1 or $\alpha$ IRS- 2 antibodies, separated by SDSPAGE, and immunoblotted with $\alpha P Y$ antibodies. (d and e) Association of p85 subunit of PI 3-kinase to IRS-1 and IRS-2. The same membranes used for the IRS tyrosine phosphorylation study were stripped and reblotted with $\alpha$ p 85 subunit antibody (top panels). Data (mean $\pm \mathrm{SD} ; n=4$ ) in b-e are expressed as relative to control, assigning a value of $100 \%$ to the lean insulin mean. ${ }^{*} P<0.05,{ }^{*} P<0.01$, insulin lean vs. insulin obese.

respectively, in the aorta of lean rats (Figure 3, $\mathrm{b}$ and c), compared with increases of 1.9- and 2.5 -fold, respectively, in the aorta of obese rats $(P<0.005$; Figure $3, \mathrm{~b}$ and $\mathrm{c})$, representing decreases of $65 \%$. The same membranes used to detect tyrosine phosphorylation of IRS-1 and IRS-2 were reblotted with antibodies against p85 subunit of PI 3-kinase. In the lean rats increases of 3.7- and 4.5-fold in p85 association to IRS-1 and IRS-2, respectively, were induced by insulin (Figure 3, d and e), whereas only 1.6- and 1.9-fold increases were observed in the aorta of obese rats, reductions of $71-74 \%$ $(P<0.01)$.

Ex vivo stimulation of PI 3-kinase activity in aorta and microvessels. Basal and insulin-stimulated PI 3-kinase activities were compared in IRS-1 or IRS-2 immunoprecipitates from the aorta and enriched microvessels of lean and obese rats in ex vivo experiments. Insulin (100 nM) increased IRS-1- and IRS-2-associated PI 3kinase activities by 3.6- and 5.8-fold $(n=4)$ over the basal level in the aorta of lean rats (Figure 4 , a and b), respectively, whereas insulin only stimulated increases of 1.8- and 2.1-fold in the aorta of obese rats. Thus, insulin-stimulated activities of PI 3-kinase associated with IRS-1 and IRS-2 were reduced by 69 and 77\%, respectively, in the aorta of obese rats, compared with the lean rats. Insulin at 2 and $100 \mathrm{nM}$ increased IRS-2-associated PI 3-kinase activities in enriched microvessels by 4- and 9-fold in lean rats and increased by only 1.5 - and 3.5 -fold in the obese rats, respectively (Figure 4c).

Using immunoblotting analysis, no differences were noted between the total protein levels of the p 85 subunit of PI 3-kinase in the aorta and microvessels from lean and obese rats. Similarly, no differences were detected between total PI 3-kinase activities in the aorta from lean and obese rats, as quantified by immunoprecipitation with anti-
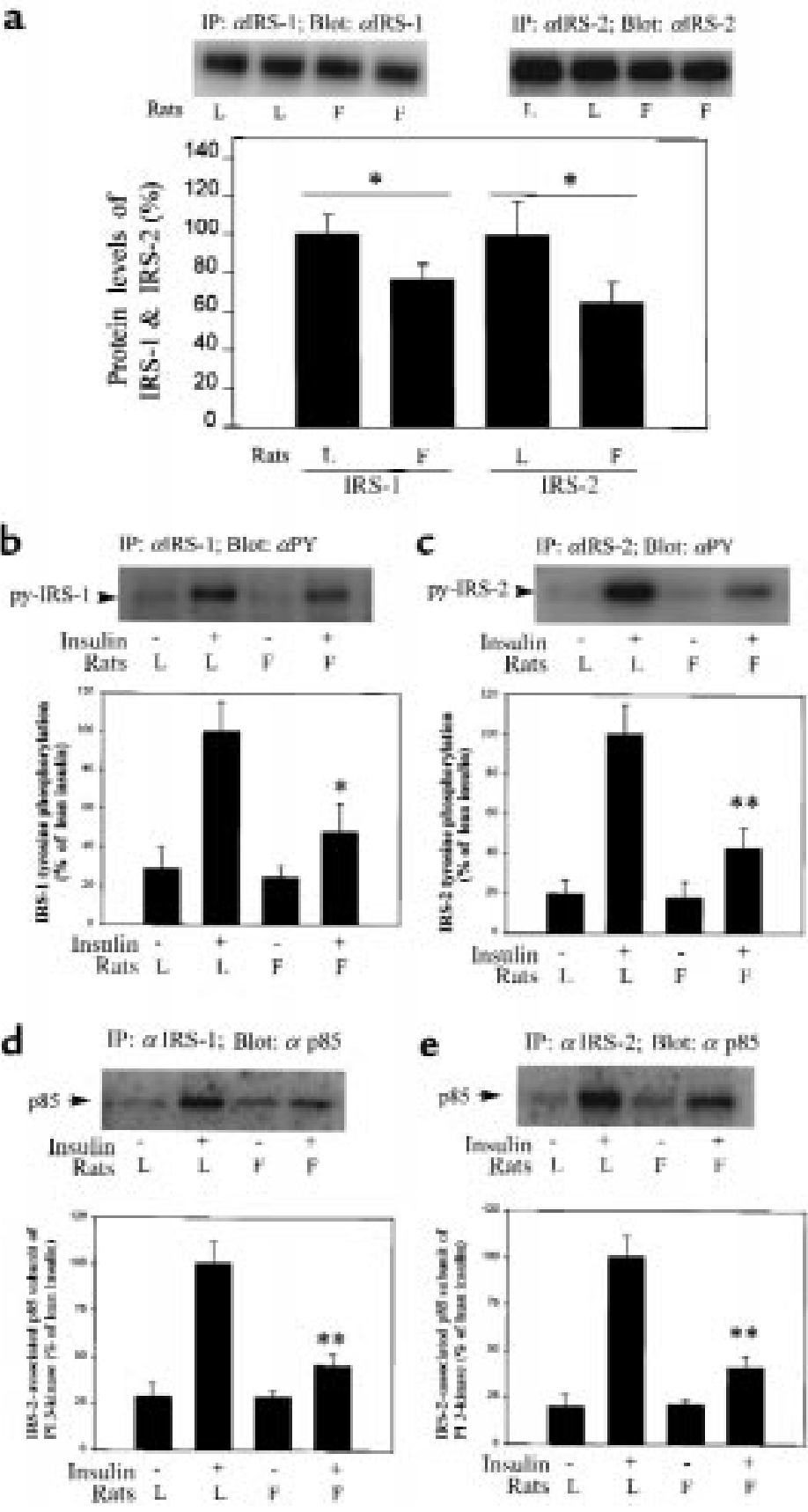

bodies to p85 subunit of PI 3-kinase (data not shown).

Insulin-stimulated serine phosphorylation of Akt/PKB in microvessels ex vivo. Akt is a serine/threonine kinase that is serine phosphorylated and can be activated by insulin through the PI 3-kinase pathway (34). In the microvessels from lean rats, insulin at 2 and $100 \mathrm{nM}$ increased serine phosphorylation of Akt by 11- and 21-fold over the basal levels, respectively (Figure 5). However, in the microvessels from obese rats, insulin increased Akt serine phosphorylation by only 5 - and 12 -fold over the basal levels, respectively, reductions of $60 \%$ and $45 \%$ compared with lean rats.

Physiological parameters of lean fa/ + and obese fa/fa Zucker rats used for englycemic byperinsulinemic clamp studies. Lean and obese rats were divided into insulin-treated and con- 
a

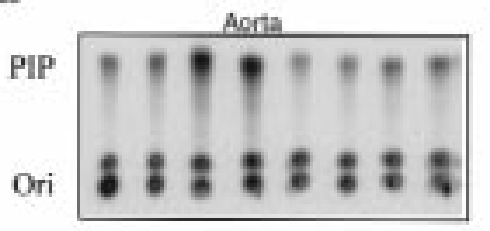

b
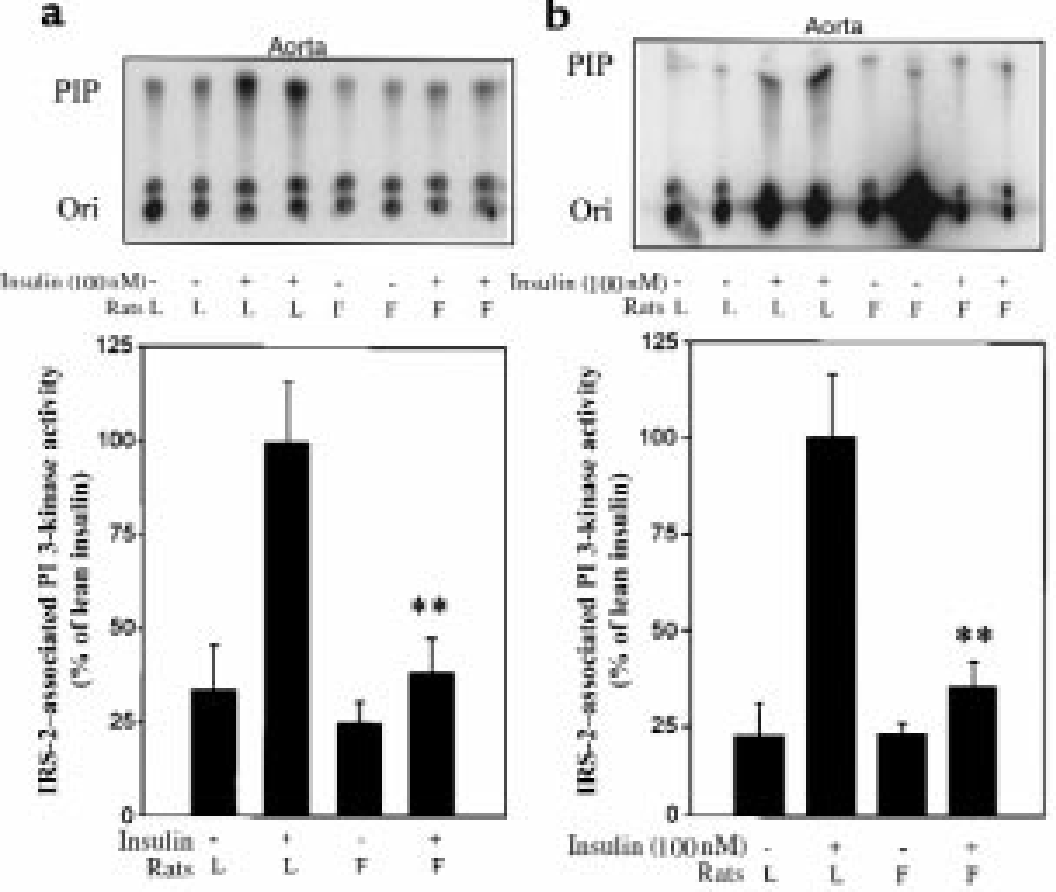
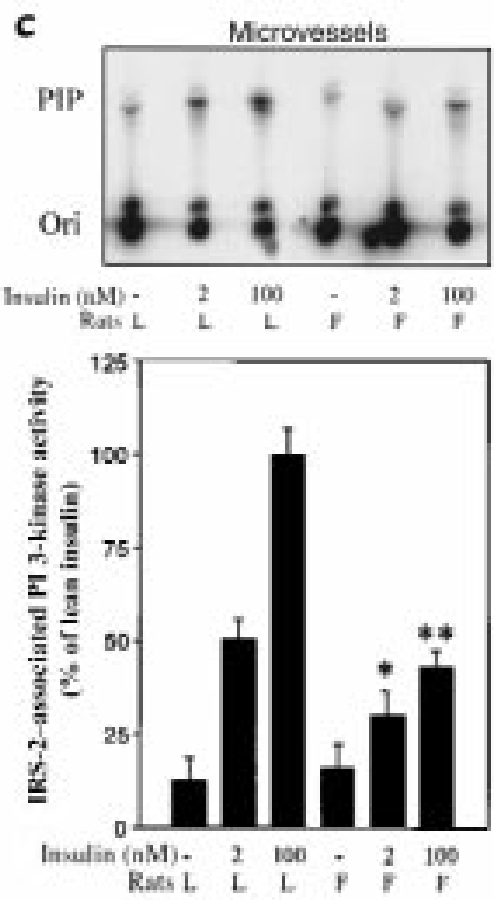

Figure 4

IRS-1- and IRS-2-associated PI 3-kinase activities in the aorta and microvessels ex vivo. Isolated aortas were incubated without or with insulin (100 nM) in $\operatorname{DMEM}(0.1 \% \mathrm{BSA})$ for 30 minutes at $37^{\circ} \mathrm{C}$. Equal amounts of protein $(2 \mathrm{mg})$ samples were subjected to immunoprecipitation with $\alpha$ IRS-1 (a) or $\alpha$ IRS-2 (b) antibodies. In the studies with microvessels (c), samples were treated without or with insulin (2-100 nM) in DMEM (0.1\% BSA) for 5 minutes at $37^{\circ} \mathrm{C}$, and $2-\mathrm{mg}$ protein samples were subjected to immunoprecipitation with $\alpha \mathrm{IRS}-2$ antibody. The kinase activities were measured in the presence of phosphatidylinositol and [ $\left.{ }^{32} \mathrm{P}\right]$ ATP, and the lipid products were separated by TLC (top panels). The spots that comigrated with a PI 3-phosphate (PIP) standard were quantified by a Phosphorlmager. Data (mean \pm SD; $n=4$ ) are expressed as relative to control, assigning a value of $100 \%$ to the mean of $100-\mathrm{nM}$ insulin-treated samples of lean rats. ${ }^{*} P<0.05,{ }^{*} P<0.01$, lean vs. obese treated with insulin at the same concentrations.

trol groups, infused either with $10 \mathrm{mU} / \mathrm{kg} / \mathrm{min}$ insulin or saline, respectively. During the study, blood glucose levels were monitored every 5 minutes and glucose was infused as needed to maintain blood glucose level at the preinfusion level. Fast insulin levels were $8 \pm 2$ and $262 \pm$ $52 \mu \mathrm{U} / \mathrm{mL}$ in lean and obese rats, respectively, a difference of 30 -fold. After infusion with insulin for 1 hour, serum insulin levels were significantly increased in both lean and obese rats (Table 1).

\section{Figure 5}

Insulin-stimulated serine phosphorylation of Akt in isolated microvessels ex vivo. Isolated microvessels were stimulated without or with insulin (2 and $100 \mathrm{nM})$ for 20 minutes at $37^{\circ} \mathrm{C}(n=3$; each sample of microvessels was derived from 2 rats). Tissues were homogenized in lysis buffer as described in Methods. Lysates (100 $\mu$ g protein) were separated with $8 \%$ SDS-PAGE and transferred to nitrocellulose membrane. The membranes were blotted with anti-phospho-(serine 473)-Akt antibody, viewed using an ECL kit, and quantified with a densitometer. ${ }^{*} P<0.05$, ${ }^{*} P<0.01$, lean vs. obese treated with insulin at the same concentrations $(n=3$; each sample of microvessels was derived from 2 rats).
Effect of insulin on tyrosine phosphorylation of IRs in lean and obese rats in vivo. Euglycemic clamp study 1 (8 rats in each group) was performed to determine whether insulin resistance changed insulin-stimulated tyrosine phosphorylation of IR $\beta$ in aorta and liver. Figure 6 a showed that insulin infusion increased IR $\beta$ tyrosine phosphorylation in the aorta of the lean rats by 4.2 -fold, whereas increases of only 1.8 -fold over the basal level were noted in the obese rats, a reduction of $75 \%(P<0.01)$. Similarly, insulin also
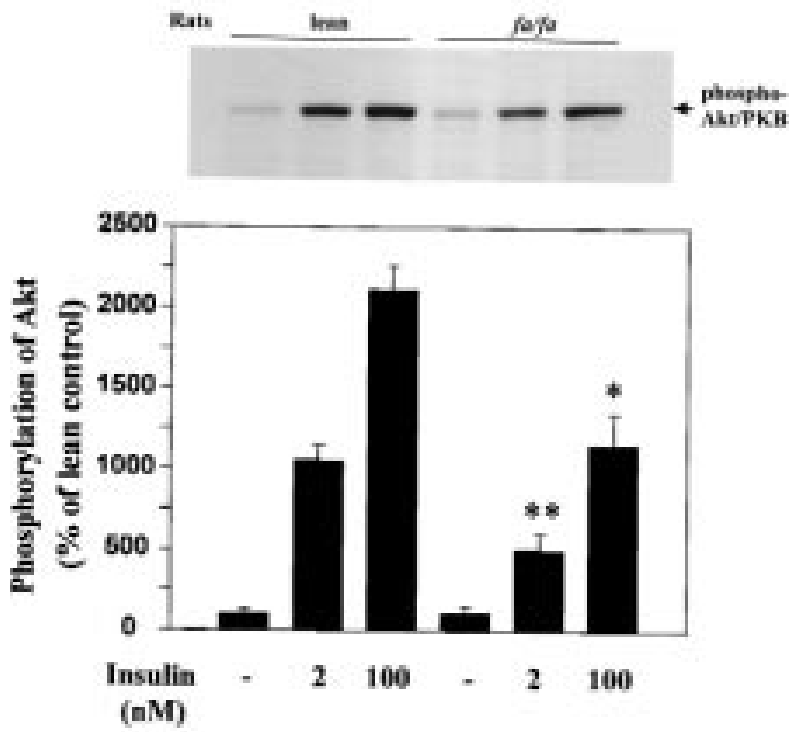
increased IR $\beta$ tyrosine phosphorylation by 7.5- and 3.0fold in the livers of the lean and obese rats, respectively, a difference of $69 \%(P<0.05)$ (Figure $6 \mathrm{~b})$. The relative abundance of IR $\beta$ subunits in the aorta and liver samples from lean and obese rats were also compared by using the same blots for the detection of IR $\beta$ tyrosine phosphorylation. As shown in Figure 6 (middle), IR $\beta$ protein levels in the aorta and liver were not different between lean and obese rats. Similarly, we did not find significant difference in IR $\beta$ protein levels in the skeletal muscle between lean and obese rats (data not shown).

The presence of IR/IGF-1 hybrid receptors was also detected in the microvessels. The abundance of hybrid receptors was significantly higher in obese than in lean rats (Figure 6c). However, the relative levels of the hybrid receptors in the microvessels accounted for only $10 \%$ and $16 \%$ of the total IR in lean and obese rats, respectively.

Effect of insulin on PI 3-kinase activities in lean and obese rats in vivo. Euglycemic clamp study 2 (5 rats in each group) was performed to determine the effect of insulin resistance on PI 3-kinase activation by insulin. As illustrated in Figure 7a, the mean levels of basal PI 3-kinase activities in the anti-IRS-2 immunoprecipitates were comparable in the aorta of lean and obese rats $(P=0.10 ; n=5)$. Infusion with insulin $(10 \mathrm{mU} / \mathrm{kg} / \mathrm{min}$ for 1 hour $)$ increased IRS-2-associated PI 3-kinase activities by 3.5fold in the aorta of lean rats, compared with increases of only 1.7-fold in obese Zucker rats, a reduction of $72 \%$ ( $P<0.01 ; n=5$ in each group).

In the liver, the basal levels of PI 3-kinase activities of obese rats were significantly increased by $38 \%$, compared with lean rats $(P<0.05 ; n=5)$. Insulin increased IRS2 -associated PI 3-kinase activities $(P<0.01 ; n=5)$ by 4.5- and 1.6-fold in the livers of lean and obese rats, respectively, a reduction of $82 \%(P<0.01 ; n=5$ in each group) (Figure $7 \mathrm{~b}$ ).

Tyrosine phosphorylation of MAP kinase (ERK-1/2) in vascular tissues. Using antibodies against tyrosine-phosphorylated ERK-1/2, the levels of ERK-1/2 activation were examined in enriched microvessels after insulin stimulation in ex vivo experiments. As shown in Figure 8 (top), insulin ( 2 or $100 \mathrm{nM}$ ) stimulated tyrosine phosphorylation of ERK-1/2 equally in microvessels of both lean and obese rats. Insulin at 2 and $100 \mathrm{nM}$ stimulated 3.0- and 4.3-fold increases above basal levels in tyrosine phosphorylation of ERK-1/2 in microvessels of lean rats, respectively (Figure 8, bottom), and 3.4- to 4.5-fold increases in the obese rats. The basal levels of tyrosine phosphorylation of ERK-1/2 were significantly higher in microvessels of obese rats than lean animals $(P<0.05$; $n=6)$. No significant differences in ERK- $1 / 2$ protein levels in microvessels of obese and lean animals were observed (Figure 8, middle).

ERK-1/2 tyrosine phosphorylations were examined in the aorta and liver after euglycemic hyperinsulinemic clamp. Insulin infusion did not stimulate tyrosine phosphorylation of ERK-1/2 in the aorta and liver from lean and obese rats. Interestingly, the basal levels of phosphorylated ERK-1/2 in the aorta and liver of obese rats were 2.2 -fold $(P<0.05 ; n=5)$ and 2.6 -fold $(P<0.01 ; n=5)$ higher, respectively, than those from lean controls (data not shown). The protein levels of ERK-1/2 were not sig- $\mathbf{a}$
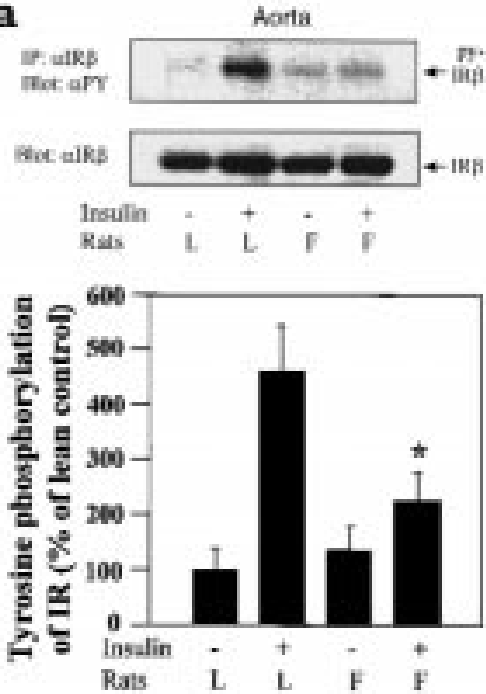

b
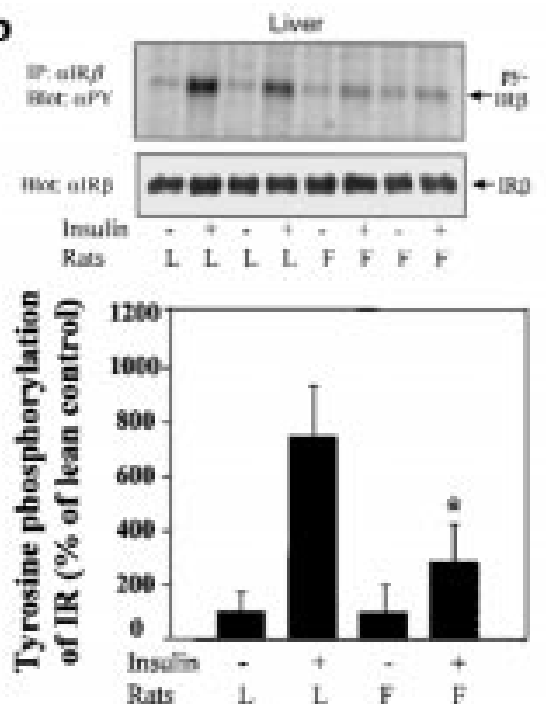

c
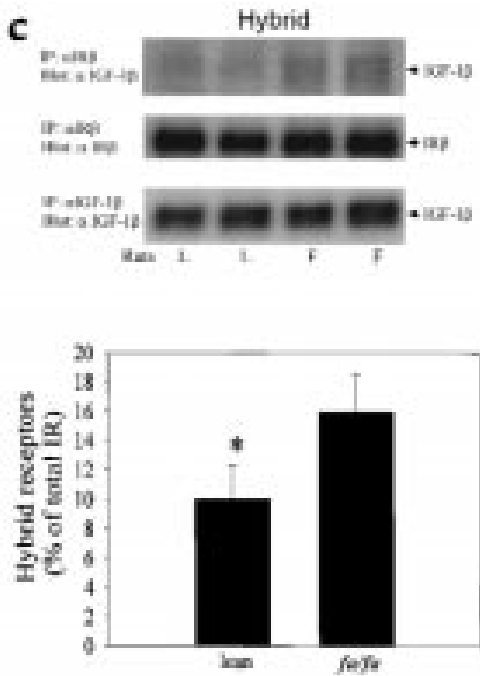

Figure 6

( $\mathbf{a}$ and $\mathbf{b}$ ) Tyrosine phosphorylation and protein levels of IR $\beta$ in the aorta and liver after euglycemic hyperinsulinemic clamp. Animals were infused with saline (control) or insulin ( $10 \mathrm{mU} / \mathrm{kg} / \mathrm{min}$ ) for 1 hour during a euglycemic clamp as described in Methods. The aorta and liver were removed, and equal amounts of protein were subjected to immunoprecipitation with IR $\beta$ antibody, separated by SDS-PAGE, and immunoblotted with $\alpha$ PY antibody (top panels). Stripped membranes were reblotted with $\alpha \mathrm{IR} \beta$ antibody (middle panels). Data (mean \pm SD; $n=4$ ) are expressed as relative to control, assigning a value of $100 \%$ to the lean control mean. ${ }^{*} P<0.05$, insulin lean vs. insulin obese. (c) Hybrid IR/IGF-1R in microvessels of lean and obese rats. Isolated microvessels were homogenized, and lysates ( $6 \mathrm{mg}$ protein) were subjected to immunoprecipitation with $\alpha$ IR $\beta$ or IGF-1R $\beta$ antibodies, separated by SDS-PAGE, and immunoblotted with $\alpha$ IGF-1R $\beta$ or $\alpha \operatorname{IR} \beta$ antibodies as indicated. Stripped membranes were reblotted with $\alpha$ IR $\beta$ antibody (middle). The percentage of hybrid receptors in total IR was calculated by the ratio between Phosphorlmager counting of IGF-1R $\beta$ bands (top) and IR $\beta$ bands (middle) in $\alpha \mathrm{IR} \beta$ immunoprecipitates. ${ }^{*} P<0.05$, lean vs. obese rats $(n=3$; each sample of microvessels was derived from 2 rats). 


\section{Figure 7}

IRS-2-associated PI 3-kinase activities in the aorta and liver after euglycemic hyperinsulinemic clamp. Animals were infused with saline (control) or insulin (10 $\mathrm{mU} / \mathrm{kg} / \mathrm{min}$ ) for 1 hour during a euglycemic clamp as described in Methods. IRS-2 associated PI 3-kinase in the aorta, and liver was immunoprecipitated with $\alpha \mathrm{IRS}-2$ antibody. The kinase activities were measured in the presence of phosphatidylinositol and [ $\left.{ }^{32} \mathrm{P}\right]$ ATP, and the lipid products were separated by TLC (top panels). The spots that comigrated with PIP standard were quantified by a Phosphorlmager. Data (mean $\pm \mathrm{SD} ; n=5$ ) are expressed relative to control, assigning a value of $100 \%$ to the control mean. ${ }^{*} P<0.05$, insulin lean vs. insulin obese. a
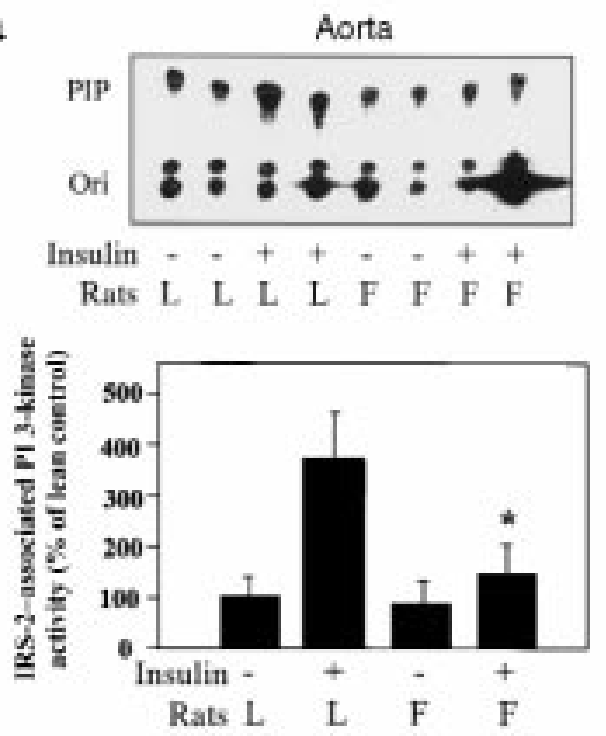

b

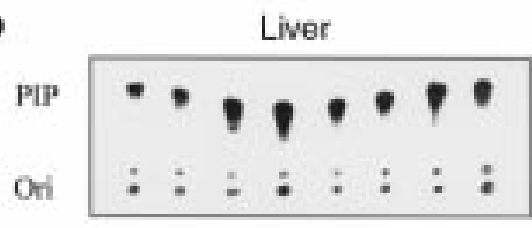

Insulin - + + + + +

Rats L. L L L F F $F$ F

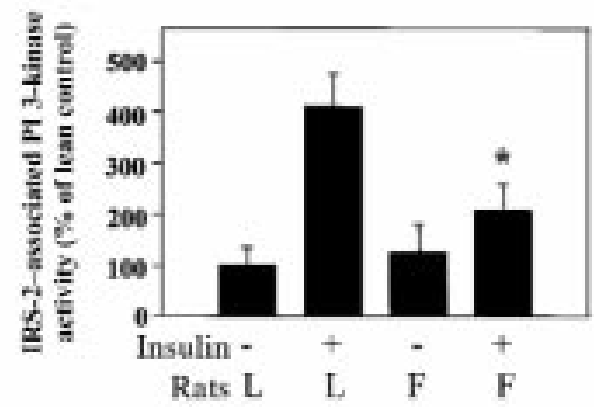

nificantly different in the aorta and liver between lean and obese animals.

\section{Discussion}

In the present study we have characterized insulin signaling in the aorta and microvessels of lean and obese Zucker $f a / f a$ rats. The obese Zucker rats have insulin resistance, hyperinsulinemia, hyperlipidemia, glucose intolerance, and mild hypertension, properties similar to obesity-related insulin resistance and type 2 diabetes mellitus (35). These results show that tyrosine phosphorylation of IR and IRS-1/2, PI 3-kinase activity, and serine phosphorylation of Akt/PKB are impaired in the vasculature of the obese animals. However, insulin stimulates tyrosine phosphorylation of ERK-1/2 MAP kinase equally in the microvessels of both lean and obese rats, although the basal levels of tyrosine phosphorylation of MAP kinase are significantly higher in the aorta and microvessels of the obese rats than in lean rats. Thus, we believe, these results have provided the first quantitative analysis of insulin-signaling pathways in intact vascular tissues, and have demonstrated a selective impairment of insulin's activation on the PI 3-kinase-Akt pathway in the obese and insulin-resistant animals. In addition, both endothelial and smooth muscle cells are probably contributing to the parameters of the insulin signal measured in this study. We have previously reported that insulin can increase PI 3 -kinase activation through IRS-1/2 in smooth muscle cells (30); recently, we have found that endothelial cells have the same properties (data not shown).

The sites of insulin-signaling impairment appear to be at the IR and postreceptor levels in the aorta and microvessels of obese Zucker rats. Although the total amount of the receptors are not changed, the levels of IR tyrosine phosphorylation induced by insulin are decreased significantly in the blood vessels of obese Zucker rats (as examined by both in vivo and ex vivo studies) compared with lean rats. The reduction in IR tyrosine phosphorylation in the vascular cells is similar to that observed in liver, as examined by hyperinsulinemic euglycemic clamp study. Interestingly, the amount of IR/IGF$1 \mathrm{R}$ hybrid receptors may have been increased in the obese rats. These hybrid receptors may be less sensitive to insulin's activation because they have lower affinity for insulin binding than homodimeric IR (36). However, the contribution of the hybrid receptors to IR signaling in the vascular tissues may not be too significant, because the relative amounts of hybrid receptors to total IR were 1:10.

Possibly as a result of the decreased IR tyrosine phosphorylation, IRS-1 and IRS- 2 tyrosine phosphorylation and PI 3-kinase activation in the aorta and microvessels of the obese Zucker rats are decreased. Decreases in protein levels of IRS-1 and IRS-2 by $23-34 \%$ in vascular tissues of the obese Zucker rats also contribute to the decline in PI 3-kinase activities. However, the total protein levels of PI 3-kinase and the total activities of PI 3-kinase immunoprecipitated with anti-p85 antibody are not altered in the vasculature of the obese rats, compared with lean rats. The decreases in IRS-1- and IRS-2-associated PI 3-kinase activities may be a consequence of changes in both IR kinase and decreased protein expression of IRS- 1 and IRS- 2 .

Reductions in IR phosphorylation and signaling via PI 3-kinase pathway in the vascular tissues of obese Zucker rats appear to be similar to that found in muscle, liver, and adipose tissues of insulin-resistant animal models and humans (33, 37-41). In the liver of obese Zucker fa/fa rats, insulin binding to the plasma membranes has been reported to be decreased with age in one study (42), whereas other studies noted no changes in receptor binding, although receptor tyrosine kinase activity was decreased (43). In obese patients IR numbers or binding are decreased in skeletal muscle $(40,44)$. However, insulinstimulated PI 3-kinase activity is always impaired, and protein levels of IRS- 1 and IRS-2 are decreased in muscle and liver of obese Zucker rats (38). In diabetic $o b / o b$ mice, decreases in receptor tyrosine phosphorylation, IRS-1 tyrosine phosphorylation, and PI 3-kinase activation in liver and skeletal muscles are associated with the reduc- 
tion in protein expression of IR, IRS- 1 and IRS-2, and p85 subunit of PI 3-kinase $(33,41)$. In contrast, we did not find changes in protein expression of IR $\beta$ and $p 85$ subunit of PI 3-kinase in vascular tissues of the obese Zucker rats. This difference could be because our results quantified total amount of IR rather than just that on the plasma membrane. In addition, it is possible that insulin resistance can be induced even without changes in IR protein level. For example, it has been reported that TNF- $\alpha$ inhibits IR signaling at IR and IRS- 1 tyrosine phosphorylation without changing IR protein levels (45).

There are probably several mechanisms that can cause decreases in insulin signaling via the PI 3-kinase pathway in the vasculature of obese insulin-resistant rats. First, increases in serine and threonine phosphorylation of IR $\beta$ may reduce receptor kinase activity and autophosphorylation. It has been reported that activation of PKC induces serine phosphorylation of IR, which can inhibit its tyrosine kinase activity, and leads to the decreases of insulin-induced PI 3-kinase activities both in vascular cells and nonvascular cells $(46,47)$. Activation of protein kinase $C-\alpha,-\beta,-\varepsilon$, and $-\delta$ have been reported in skeletal muscle of Zucker obese and diabetic Goto-Kakizaki rats (48). Second, altered phosphotyrosine phosphatase activity might lead to reduction in tyrosine phosphorylation of IR and IRS protein that secondarily decreases PI 3-kinase activity. Both increase and decrease in phosphotyrosine phosphatase activities have been reported in skeletal muscle and/or adipose tissue of Zucker obese rats and in obese and type 2 diabetic patients (49-51). Third, dyslipidemia may play a role in mediating insulin resistance observed in Zucker obese rats. Recent studies suggested that experimentally induced hypertriglyceridemia and high plasma free fatty acid levels impair in vivo insulin's metabolic action $(52,53)$. Last, circulating factors and hormone may also regulate insulin signaling in the vasculature. These cytokines include TNF- $\alpha$ and TNF- $\beta$, angiotensin II, and endothelin-1. TNF- $\alpha$ has been suggested as an important mediator of insulin resistance in obese animals through its overexpression from fat tissue (45). Angiotensin II has been reported to inhibit insulin signaling through modulating IRS protein phosphorylation and/or PI 3-kinase activity (54). Our recent study has also demonstrated that endothelin-1, which is elevated in type 2 diabetes, attenuated insulin-stimulated PI 3-kinase activity in cultured VMSCs (30).

Selective impairment of insulin signaling on PI 3-kinase pathway in the vascular tissues could be pathophysiologically important in the development of cardiovascular diseases. A recent study by Zeng and Quon showed that activation of PI 3-kinase pathway could be involved in insulin's stimulatory effect on $\mathrm{NO}$ release in cultured vascular endothelial cells (3). This effect of insulin on NO could be responsible for insulin's vasodilatory actions $(7,8)$. In an insulin-resistant state, the vasodilatation induced by insulin is blunted because the PI 3-kinase pathway is partially inhibited. Interestingly, the vasodilatory effect of insulin is also blunted in subjects with obesity and patients with type 2 diabetes (12). In addition, we have recently reported that insulin's vasodilatory effect could be partially due to increases in eNOS gene expression via PI 3-kinase pathway (6). Besides vasodilatory actions, stimulation of NO production by insulin may also affect vascular remodeling, such as inhibiting VSMC proliferation and migration and inhibiting platelet aggregation and leukocyte adhesion to endothelial cells (55). These reports suggest that the inhibition of PI 3-kinase pathway activation by insulin in vascular tissues of insulin-resistant states may contribute to the loss of insulin's effect on NO production, which will enhance the atherogenic potential of the insulin-resistant state.

In contrast to PI 3-kinase activation, much less is known about insulin's activation of ERK-1/2 MAP kinase in insulin-resistant or diabetic conditions in vivo. Our results have established that insulin at physiological levels can activate MAP kinase in microvessels, although to a modest level. Surprisingly, the effect of insulin on ERK-1/2 MAP kinase tyrosine phosphorylation is not observed in the aorta and liver in vivo by using the euglycemic clamp. This could be the result of the lack of an effective way to isolate the MAP kinase pool specifically activated by insulin in euglycemic clamp studies. Alternatively, manipulation of the tissues during isolation could have artificially activated MAP kinase and mimicked insulin's effect. Because insulin's effect on MAP kinase is relatively weak compared with other growth factors such as PDGF, it is possible that insulin growth effect mediated by MAP kinase activation may not be pathophysiologically important. This is consistent with insulin being a very weak stimuli of vascular cell proliferation at physiological concentrations, compared with other growth factors (56).
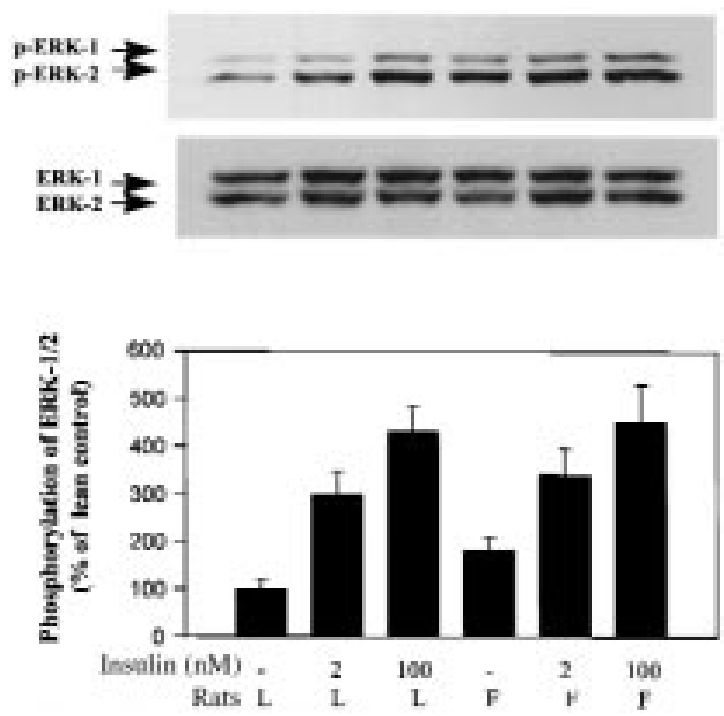

\section{Figure 8}

Effects of insulin on tyrosine phosphorylation of MAP kinase (ERK$1 / 2$ ) in microvessels ex vivo. Isolated microvessels were incubated without or with insulin (2 or $100 \mathrm{nM}$ ) in DMEM $(0.1 \% \mathrm{BSA})$ for 10 minutes at $37^{\circ} \mathrm{C}$. Fifty micrograms of protein of each sample was separated by SDS-PAGE and immunoblotted with antibody specific for tyrosinephosphorylated ERK-1/2. Stripped membranes were reblotted with polyclonal antibody against ERK-1/2 proteins. Data (mean \pm SD; $n=6)$ are expressed relative to control, assigning a value of $100 \%$ to lean control mean. 
We believe that these studies have provided the first direct evidence that insulin can activate both the PI 3kinase and MAP kinase pathways in the vasculature ex vivo or in vivo. In an insulin-resistant state, PI 3-kinase pathway appears to be selectively blunted in vascular tissues, compared with MAP kinase activity. These findings have provided support for the hypothesis that under physiological states, insulin may have vasodilatory and antiatherogenic actions mediated by the PI 3-kinase-NO pathway, although activation of PI 3-kinase may also stimulate DNA synthesis (20). In the obese insulin-resistant state, insulin's vasodilatory and antiatherogenic functions, mediated through PI 3-kinase pathway, may be impaired, whereas proatherogenic actions mediated through MAP kinase cascade may be increased due to hyperinsulinemia and plasma mitogenic factors. The imbalance between PI 3-kinase and MAP kinase signal pathways in the vasculature may lead to the development of cardiovascular abnormality observed in insulin resistance and diabetic patients.

\section{Acknowledgments}

This study was supported in part by National Institutes of Health (NIH) grant DK-53105 (to G.L. King) and by Diabetes and Endocrinology Research Center grant DK36836 (to the Joslin Diabetes Center). We appreciate the excellent technical assistance of Christopher de Souza and Michael F. Hirshman (Joslin Diabetes Center). Z.Y. Jiang is a recipient of Mary K. Iacocca Fellowship and NIH Training Fellowship.

1. Obata, T., et al. 1996. Insulin signaling and its regulation of system A amino acid uptake in cultured rat vascular smooth muscle cells. Circ. Res. 79:1167-1176.

2. King, G.L., Goodman, D., Buzney, S., Moses, A., and Kahn, C.R. 1985 Receptors and growth-promoting effects of insulin and insulinlike growth factors on cells from bovine retinal capillaries and aorta. J. Clin. Invest. 75:1028-1036.

3. Zeng, G., and Quon, M.J. 1996. Insulin-stimulated production of nitric oxide is inhibited by Wortmannin. Direct measurement in vascular endothelial cells. J. Clin. Invest. 98:894-898.

4. Tamaroglio, T.A., and Lo, C.S. 1994. Regulation of fibronectin by insulin-like growth factor- 1 in cultured rat thoracic smooth muscle cells and glomerular mesangial cells. Exp. Cell Res. 21:338-346.

5. Anderson, P.W., et al. 1996. Insulin and angiotensin II are additive in stimulating TGF $\beta 1$ and matrix mRNAs in mesangial cells. Kidney Int. 50:745-753.

6. Kuboki, K., et al. 1998. Mechanism of insulin's effect on endothelial nitric oxide synthase (eNOS) expression in vivo and in vitro. Diabetes. 47(Suppl. 1):A24. (Abstr.)

7. Steinberg, H.O., Brechtel, G., Johnson, A., Fineberg, N., and Baron, A.D 1994. Insulin-mediated skeletal muscle vasodilation is nitric oxide dependent. A novel action of insulin to increase nitric oxide release. $J$. Clin. Invest. 94:1172-1179.

8. Scherrer, U., Randin, D., Vollenweider, P., Vollenweider, L., and Nicod, P. 1994. Nitric oxide release accounts for insulin's vascular effects in humans. J. Clin. Invest. 94:2511-2515.

9. Reaven, G.M. 1993. Role of insulin resistance in human disease (syndrome X): an expanded definition. Annu. Rev. Med. 44:121-131.

10. Despres, J.P., et al. 1996. Hyperinsulinemia as an independent risk factor for ischemic heart disease. N. Engl. J. Med. 334:952-957.

11. Howard, G., et al. 1996. Insulin sensitivity and atherosclerosis. Circulation. 93:1809-1817.

12. Steinberg, H.O., et al. 1996. Obesity/insulin resistance is associated with endothelial dysfunction. Implications for the syndrome of insulin resistance. J. Clin. Invest. 97:2601-2610.

13. DeFronco, R.A., Cooke, C.R., Andres, R., Faloona, G.R., and Davis, P.J. 1975. The effect of insulin on renal handling of sodium, potassium, calcium, and phosphate in man. J. Clin. Invest. 55:845-855.

14. Anderson, E.A., Hoffman, R.P., Balon, T.W., Sinkey, C.A., and Mark, A.L. 1991. Hyperinsulinemia produces both sympathetic neural activation and vasodilation in normal humans. J. Clin. Invest. 87:2246-2252.
15. Kasuga, M.F., Karlsson, A., and Kahn, C.R. 1982. Insulin stimulates the phosphorylation of the 95,000 -dalton subunit of its own receptor. Science. 215:185-186.

16. Sun, X.J., et al. 1991. The structure of the insulin receptor substrate IRS1 defines a unique signal transduction protein. Nature. 352:73-77.

17. Sun, X.J., et al. 1995. Role of IRS-2 in insulin and cytokine signalling. Nature. 377:173-177.

18. Skolnik, E.Y., et al. 1993. The SH2/SH3 domain-containing protein GRB2 interacts with tyrosine-phosphorylated IRS1 and Shc: implications for insulin control of ras signalling. EMBO J. 12:1929-1936.

19. Myers, M.G., Jr., et al. 1992. IRS-1 activates phosphatidylinositol 3'kinase by associating with src homology 2 domains of p85. Proc. Natl. Acad. Sci. USA. 89:10350-10354

20. Cheatham, B., et al. 1994. Phosphatidylinositol 3-kinase activation is required for insulin stimulation of pp70 s6 kinase, DNA synthesis and glucose transporter translocation. Mol. Cell. Biol. 14:4902-4911.

21. Haruta, T., et al. 1995. Insulin-stimulated GLUT4 translocation is mediated by a divergent intracellular signaling pathway. J. Biol. Chem. 270:27991-27994

22. Shepherd, P.R., Nave, B.T., and Siddle, K. 1995. Insulin stimulation of glycogen synthesis and glycogen synthase activity is blocked by wortmannin and rapamycin in 3T3-L1 adipocytes: evidence for the involvement of phosphoinositide 3-kinase and p70 ribosomal protein-S6 kinase. Biochem. J. 305:25-28.

23. Mendez, R., Myers, M.G., Jr., White, M.F., and Rhoads, R.E. 1996. Stimulation of protein synthesis, eukaryotic translation initiation factor 4E phosphorylation, and PHAS-I phosphorylation by insulin requires insulin receptor substrate 1 and phosphatidylinositol 3-kinase. Mol. Cell. Biol. 16:2857-2864.

24. Skolnik, E.Y., et al. 1993. The function of GRB2 in linking the insulin receptor to Ras signaling pathways. Science. 260:1953-1955.

25. Myers, M.G., Jr., et al. 1994. Role of IRS-1-GRB-2 complexes in insulin signaling. Mol. Cell. Biol. 14:3577-3587.

26. Sale, E.M., Atkinson, P.G., and Sale, G.J. 1995. Requirement of MAP kinase for differentiation of fibroblasts to adipocytes, for insulin activation of p90 S6 kinase and for insulin or serum stimulation of DNA synthesis. EMBO J. 14:674-684.

27. Jhun, B.H., et al. 1995. Signal transduction pathways leading to insulininduced early gene induction. Biochemistry. 34:7996-8004.

28. Kim, S.J., and Kahn, C.R. 1997. Insulin regulation of mitogen-activated protein kinase kinase (MEK), mitogen-activated protein kinase and casein kinase in the cell nucleus: a possible role in the regulation of gene expression. Biochem. J. 323:621-627.

29. King, G.L., and Johnson, S.M. 1985. Receptor-mediated transport of insulin across endothelial cells. Science. 227:1583-1586.

30. Jiang, Z.Y., et al. 1999. Endothelin-1 modulates insulin signaling through PI 3-kinase pathway in vascular smooth muscle cells. Diabetes. 48:1120-1130

31. Xi, X.P., Graf, K., Goetze, S., Hsueh, W.A., and Law, R.E. 1997. Inhibition of MAP kinase blocks insulin-mediated DNA synthesis and transcriptional activation of c-fos by Elk-1 in vascular smooth muscle cells. FEBS Lett. 417:283-286.

32. de Souza, C.J., Hirshman, M.F., and Horton, E.S. 1997. CL-316,243, a beta3-specific adrenoceptor agonist, enhances insulin-stimulated glucose disposal in nonobese rats. Diabetes. 46:1257-1263.

33. Folli, F., Saad, M.J., Backer, J.M., and Kahn, C.R. 1993. Regulation of phosphatidylinositol 3-kinase activity in liver and muscle of animal models of insulin-resistant and insulin-deficient diabetes mellitus. $J$. Clin. Invest. 92:1787-1794.

34. Brozinick, J.T., Jr., and Birnbaum, M.J. 1998. Insulin, but not contraction, activates Akt/PKB in isolated rat skeletal muscle. J. Biol. Chem. 273:14679-14682

35. Bray, G.A. 1977. The Zucker-fatty rat: a review. Fed. Proc. 36:148-153.

36. Soos, M.A., Field, C.E., and Siddle, K. 1993. Purified hybrid insulin/insulin-like growth factor-I receptors bind insulin-like growth factor-I, but not insulin, with high affinity. Biochem. J. 290:419-426.

37. Heydrick, S.J., et al. 1993. Defect in skeletal muscle phosphatidylinositol-3-kinase in obese insulin-resistant mice. J. Clin. Invest. 91:1358-1366.

38. Anai, M., et al. 1998. Altered expression levels and impaired steps in the pathway to phosphatidylinositol 3-kinase activation via insulin receptor substrates 1 and 2 in Zucker fatty rats. Diabetes. 47:13-23.

39. Freidenberg, G.R., Henry, R.R., Klein, H.H., Reichart, D.R., and Olefsky, J.M. 1987. Decreased kinase activity of insulin receptors from adipocytes of non-insulin-dependent diabetic subjects. J. Clin. Invest. 79:240-250.

40. Goodyear, L.J., et al. 1995. Insulin receptor phosphorylation, insulin receptor substrate-1 phosphorylation, and phosphatidylinositol 3kinase activity are decreased in intact skeletal muscle strips from obese subjects. J. Clin. Invest. 95:2195-2204.

41. Kerouz, N.J., Horsch, D., Pons, D., and Kahn, C.R. 1997. Differential regulation of insulin receptor substrates- 1 and -2 (IRS-1 and IRS-2) and phosphatidylinositol 3-kinase isoforms in liver and muscle of obese diabetic $(o b / o b)$ mouse. J. Clin. Invest. 100:3164-3172. 
42. Clark, J.B., and Clark, C.M., Jr. 1982. Age-related changes in insulin receptor regulation in liver membranes from Zucker fatty rats. Endocrinology. 111:964-969.

43. Hurrell, D.G., Pedersen, O., and Kahn, C.R. 1989. Alterations in the hepatic insulin receptor kinase in genetic and acquired obesity in rats. Endocrinology. 125:2454-2462.

44. Caro, J.F., et al. 1987. Insulin receptor kinase in human skeletal muscle from obese subjects with and without noninsulin dependent diabetes. J. Clin. Invest. 79:1330-1337.

45. Hotamisligil, G.S., Budavari, A., Murray, D., and Spiegelman, B.M. 1994 Reduced tyrosine kinase activity of the insulin receptor in obesity-diabetes. Central role of tumor necrosis factor-alpha. J. Clin. Invest. 94:1543-1549.

46. Chin, J.E., Dickens, M., Tavare, J.M., and Roth, R.A. 1993. Overexpression of protein kinase $C$ isoenzymes $\alpha \beta \mathrm{I}, \gamma$ and $\varepsilon$ in cells overexpressing the insulin receptor: Effects on receptor phosphorylation and signaling. J. Biol. Chem. 268:6338-6347.

47. Pillay, T.S., Xiao, S., and Olefsky, J.M. 1996. Glucose-induced phosphorylation of the insulin receptor. J. Clin. Invest. 97:613-620.

48. Avignon, A., et al. 1996. Chronic activation of protein kinase C in soleus muscles and other tissues of insulin-resistant type II diabetic Goto-Kakizaki (GK), obese/aged, and obese/Zucker rats. A mechanism for inhibiting glycogen synthesis. Diabetes. 45:1396-1404.

49. Worm, D., Handberg, A., Hoppe, E., Vinten, J., and Beck-Nielsen, H. 1996. Decreased skeletal muscle phosphotyrosine phosphatase (PTPase) activity towards insulin receptors in insulin-resistant Zucker rats meas- ured by delayed europium fluorescence. Diabetologia. 39:142-148.

50. Kusari, J., Kenner, K.A., Suh, K.I., Hill, D.E., and Henry, R.R. 1994. Skeletal muscle protein tyrosine phosphatase activity and tyrosine phosphatase $1 \mathrm{~B}$ protein content are associated with insulin action and resistance. J. Clin. Invest. 93:1156-1162.

51. Ahmad, F., Azevedo, J.L., Cortright, R., Dohm, G.L., and Goldstein, B.J. 1997. Alterations in skeletal muscle protein-tyrosine phosphatase activity and expression in insulin-resistant human obesity and diabetes. $J$. Clin. Invest. 100:449-458.

52. Boden, G., Chen, X., Ruiz, J., White, J.V., and Rossetti, L. 1994. Mechanisms of fatty acid-induced inhibition of glucose uptake. J. Clin. Invest. 93:2438-2446.

53. Roden, M., et al. 1996. Mechanism of free fatty acid-induced insulin resistance in humans. J. Clin. Invest. 97:2859-2865.

54. Folli, F., Kahn, C.R., Hansen, H., Bouchie, J.L., and Feener, E.P. 1997. Angiotensin II inhibits insulin signaling in aortic smooth muscle cells at multiple levels. A potential role for serine phosphorylation in insulin/angiotensin II crosstalk. J. Clin. Invest. 100:2158-2169.

55. Moncada, S., Palmer, R.M., and Higgs, E.A. 1991. Nitric oxide: physiology, pathophysiology, and pharmacology. Pharmacol Rev. 43:109-142.

56. Banskota, N.K., Taub, R., Zellner, K., and King, G.L. 1989. Insulin, insulin-like growth factor I and platelet-derived growth factor interact additively in the induction of the protooncogene c-myc and cellular proliferation in cultured bovine aortic smooth muscle cells. Mol. Endocrinol. 3:1183-1190. 